\title{
Compression Behavior of Confined Columns with High-Volume Fly Ash Concrete
}

\author{
Sung-Won Yoo, ${ }^{1}$ Young Cheol Choi, ${ }^{2}$ and Wonchang Choi ${ }^{2}$ \\ ${ }^{1}$ Department of Civil and Environmental Engineering, Gachon University, Seongnam-si, Gyeonggi-do 13120, Republic of Korea \\ ${ }^{2}$ Department of Architectural Engineering, Gachon University, Seongnam-si, Gyeonggi-do 13120, Republic of Korea \\ Correspondence should be addressed to Wonchang Choi; wonchang.choi@gmail.com
}

Received 10 May 2017; Accepted 18 June 2017; Published 30 July 2017

Academic Editor: Prinya Chindaprasirt

Copyright (c) 2017 Sung-Won Yoo et al. This is an open access article distributed under the Creative Commons Attribution License, which permits unrestricted use, distribution, and reproduction in any medium, provided the original work is properly cited.

\begin{abstract}
The use of fly ash in ordinary concrete provides practical benefits to concrete structures, such as a gain in long-term strength, reduced hydration heat, improved resistance to chloride, and enhanced workability. However, few studies with high-volume fly ash (HVFA) concrete have been conducted that focus on the structural applications such as a column. Thus, there is a need to promote field applications of HVFA concrete as a sustainable construction material. To this end, this study investigated the compressive behavior of reinforced concrete columns that contain HVFA with a 50 percent replacement rate. Six columns were fabricated for this study. The study variables were the HVFA replacement rate, tied steel ratio, and tie steel spacing. The computed ultimate strength by the American Concrete Institute (ACI) code conservatively predicted the measured values, and, thus, the existing equation in the ACI code is feasible for confined RC columns that contain HVFA. In addition, an analysis model was calibrated based on the experimental results and is recommended for predicting the stress-strain relationship of confined reinforced concrete columns that contain HVFA.
\end{abstract}

\section{Introduction}

Fly ash is an industrial byproduct of the electrical power industry. Recently, partially recycled fly ash has been used as supplementary cementitious material in the cement industry. Fly ash content that is less than 25 percent of the total cementitious content is now commonly used in concrete mixtures due to its apparent benefits for concrete, such as a gain in long-term strength, reduced hydration heat, improved resistance to chloride, and enhanced workability [1-4]. On a limited basis, an increase up to a 100 percent fly ash replacement rate in concrete mixtures has been attempted [5]. However, this increase in the replacement rate of cement has led to shortcomings, such as difficulties associated with adequate quality control and low early-age strength and inferior material properties [6].

Most of the previous studies on this topic have concentrated on evaluating the material properties of high-volume fly ash (HVFA) concrete and developing mix designs [3, 7]. For example, Huang et al. [8] investigated mix designs that incorporate HVFA and are associated with two types of "loss on ignition" (LOI). Huang et al. [8] confirmed the superior mechanical properties of mixtures with low LOI fly ash and the feasibility of incorporating HVFA in concrete mixtures up to 80 percent. On the other hand, with similar waterto-binder ratio in the mix design of both HVFA concrete mix and the OPC mix, less compressive strength in HVFA concrete mix will be expected [6]. In addition, limited studies have been conducted that target the use of HVFA for structural applications [9-12].

Therefore, this study focused on the compressive behavior of confined reinforced concrete (RC) columns that contain HVFA. Numerous confinement models are available in the literature [13-15] to evaluate the axial capacity and to predict the envelope of the stress-strain relationship for RC columns. However, HVFA in concrete results in inferior structural performance in terms of early-age strength. To develop an accurate stress-strain model, the proper material properties must be considered. This paper presents the results of a seriespagebreak of tests of RC columns that contain HVFA and proposes an analysis model to predict the behavior of RC columns according to HVFA content. 
TABLE 1: Chemical proportion for OPC and FA.

\begin{tabular}{|c|c|c|c|c|c|c|c|c|c|}
\hline \multirow{3}{*}{ Types } & \multicolumn{9}{|c|}{ Items } \\
\hline & \multicolumn{7}{|c|}{ Chemical composition [\%] } & \multicolumn{2}{|c|}{ Physical properties } \\
\hline & $\mathrm{SiO}_{2}$ & $\mathrm{Al}_{2} \mathrm{O}_{3}$ & $\mathrm{Fe}_{2} \mathrm{O}_{3}$ & $\mathrm{CaO}$ & $\mathrm{MgO}$ & $\mathrm{SO}_{3}$ & Ig. loss & Specific gravity $\left[\mathrm{g} / \mathrm{cm}^{3}\right]$ & Blaine $\left[\mathrm{cm}^{2} / \mathrm{g}\right]$ \\
\hline NPC & 21.96 & 5.27 & 3.44 & 63.41 & 2.13 & 1.96 & 0.79 & 3.16 & 3,214 \\
\hline $\mathrm{FA}$ & 55.66 & 27.76 & 7.04 & 2.70 & 1.14 & 0.49 & 4.3 & 2.19 & 3,621 \\
\hline
\end{tabular}

TABle 2: Mix designs for OPC and HVFAC.

\begin{tabular}{|c|c|c|c|c|c|c|c|c|}
\hline \multirow{2}{*}{ Binder type } & \multirow{2}{*}{$\mathrm{W} / \mathrm{B}(\%)$} & \multirow{2}{*}{ S/a (\%) } & \multicolumn{5}{|c|}{ Unit weight $\left(\mathrm{kg} / \mathrm{m}^{3}\right)$} & \multirow{2}{*}{ Superplasticizer (\% by cement weight) } \\
\hline & & & $\mathrm{W}$ & $\mathrm{C}$ & FA & S & G & \\
\hline OPC & 50.0 & 40.2 & 175 & 350 & 0 & 710 & 1,054 & 0.05 \\
\hline HVFAC & 35.0 & 44.1 & 120 & 154 & 189 & 821 & 1,042 & 1.50 \\
\hline
\end{tabular}

Note. S/a is the sand-to-aggregate ratio; $\mathrm{W}$ is water; $\mathrm{C}$ is cement; FA is fly ash; $\mathrm{S}$ is sand; $\mathrm{G}$ is gravel.

TABLE 3: Testing matrix.

\begin{tabular}{|c|c|c|c|c|c|}
\hline ID & Longitudinal steel ratio (\%) & Tied steel ratio (\%) & Tied steel spacing $(\mathrm{mm})$ & $f_{c}(\mathrm{MPa})$ & Fly ash (\%) \\
\hline $\mathrm{N}-100$ & \multirow{6}{*}{2.25} & 0.475 & 100 & \multirow{3}{*}{30.6} & \multirow{3}{*}{0} \\
\hline N-150 & & 0.317 & 150 & & \\
\hline $\mathrm{N}-250$ & & 0.190 & 250 & & \\
\hline F-100 & & 0.475 & 100 & \multirow{3}{*}{30} & \multirow{3}{*}{55} \\
\hline F-150 & & 0.317 & 150 & & \\
\hline F-250 & & 0.190 & 250 & & \\
\hline
\end{tabular}

Six columns were manufactured for this study. The study variables are the replacement rate of the fly ash, the tied steel ratio, and tie steel spacing. In addition, based on the experimental results, an analysis model was developed to predict the compressive behavior of RC columns that contain HVFA. Comparisons of the model results with the test results were used to calibrate the accuracy of the proposed analysis model for HVFA RC columns.

\section{Experimental Program}

2.1. Test Parameters and Specimen Fabrication. Tests were conducted based on two replacement ratios of fly ash $(0 \%$ and $50 \%)$ as the variables. The design compressive strength of the concrete was $30 \mathrm{MPa}$. The longitudinal rebar reinforcement ratio was fixed at 2.25 percent with three different spacings $(100 \mathrm{~mm}, 150 \mathrm{~mm}$, and $250 \mathrm{~mm})$ of tie rebar in the column specimens. The rebar sizes of D13 $(\phi=13 \mathrm{~mm})$ and D10 $(\phi=10 \mathrm{~mm})$ were used for the longitudinal rebar and tie rebar, respectively. The measured yield strength of D13 rebar is $412 \mathrm{MPa}$. And the chemical composition of fly ash in the study was presented in Table 1. Extra process was performed to ensure quality control of fly ash and the loss of ignition values was controlled to $5 \%$ or less.

Table 2 shows the mix design for ordinary Portland cement (OPC) and high-volume fly ash concrete (HVFAC). Due to the low water-to-binder ratio (W/B), a relatively large amount of superplasticizer was used in the HVFAC mix. The use of fly ash in OPC provides practical benefits to concrete, such as a gain in long-term strength, reduced hydration heat, improved resistance to chloride, and enhanced workability. The mix proportion used in this study has been developed based on the related research results by the authors [16]. To determine material properties of concrete, three cylindrical specimens $(100 \mathrm{~mm} \times 200 \mathrm{~mm})$ were made and cured in moisture condition for 28 days with $23^{\circ} \mathrm{C} \pm 3$.

Table 3 shows the variables for the specimens: tie steel ratio, spacing of the tied steel, and the replacement rate of the fly ash. The specimen identification (ID) indicates the fly ash and tie steel spacing; for example, N-100 means that the specimen is fabricated with OPC with $100 \mathrm{~mm}$ of tie steel spacing.

Each specimen cross-section is $150 \mathrm{~mm} \times 150 \mathrm{~mm}$ at the midheight of the column and is $1,030 \mathrm{~mm}$ in height. The column specimens were cured in moisture for 28 days with $23^{\circ} \mathrm{C} \pm 3$. Compression tests were performed at the age of 28 days after fabrication. Figure 1 presents the reinforcement details of a specimen, the installed gauge locations, and the test set-up used in this study.

2.2. Test Procedure. A universal testing machine (UTM) with $2,000 \mathrm{kN}$ was used to apply monotonic axial compressive loading with displacement control at a rate of $0.5 \mathrm{~mm} / \mathrm{min}$ (cross-head speed). To monitor the strain of the concrete 


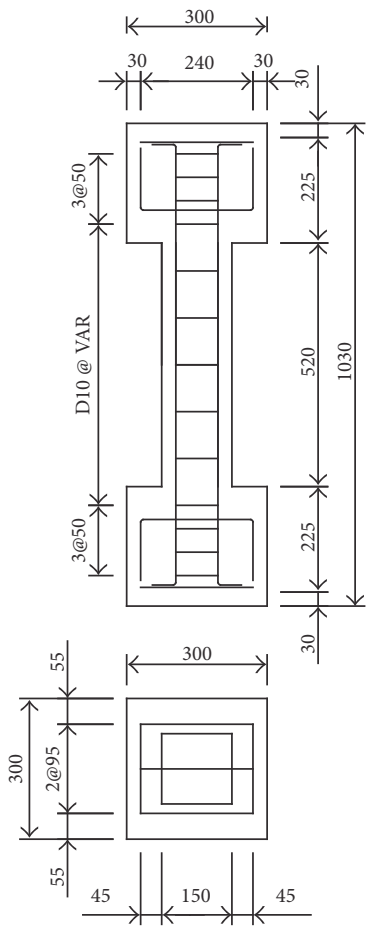

(a) Specimen dimensions

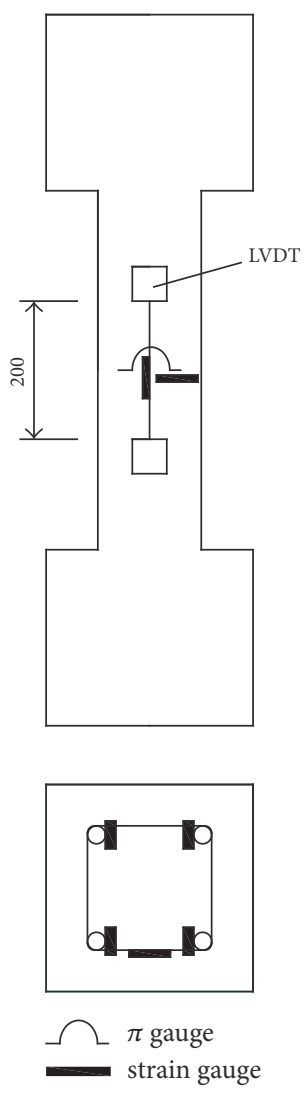

(b) Gauge locations

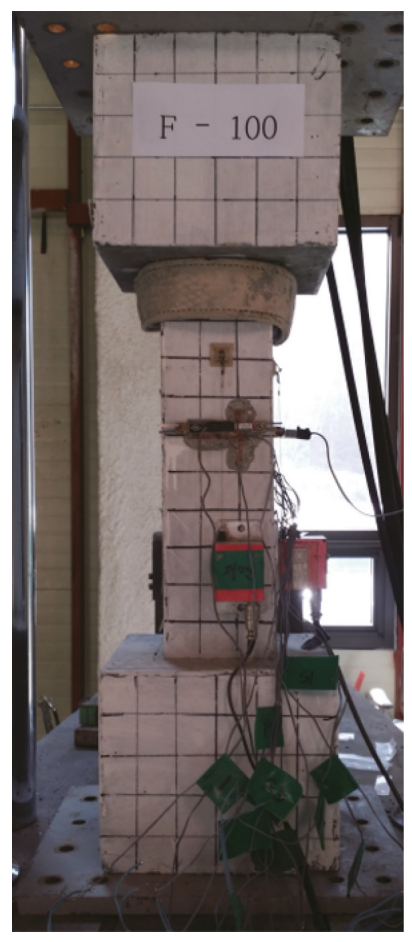

(c) Test set-up

FIGURE 1: Specimen design and instrumentation.

TABLE 4: Material properties of concrete mixtures.

\begin{tabular}{|c|c|c|c|c|c|c|}
\hline \multirow{2}{*}{ ID } & \multirow{2}{*}{$f_{c}(\mathrm{MPa})$} & \multirow{2}{*}{$\varepsilon_{c}$} & \multirow{2}{*}{ Unit weight $\left(\mathrm{kg} / \mathrm{m}^{3}\right)$} & \multicolumn{3}{|c|}{$E_{c}(\mathrm{MPa})$} \\
\hline & & & & Measured & ACI 318 & Meas./Pred. \\
\hline OPC & 30.6 & 0.00285 & 2,304 & 28,918 & 26,522 & 1.09 \\
\hline HVFAC & 30.0 & 0.00287 & 2,102 & 21,173 & 23,058 & 0.92 \\
\hline
\end{tabular}

surface and the displacement of the column, strain gauges, a pressure indicator (PI) gauge, and a linear variable displacement transducer (LVDT) were installed at the midheight of the column, as shown in Figure 1(b). Strain gauges also were installed on the longitudinal rebar and the tie rebar. Monotonic loading tests were terminated when an abrupt load drop was observed for each specimen.

\section{Test Results and Discussion}

3.1. Material Properties. Figure 2 presents the stress-strain relationship for the OPC and HVFAC specimens. Table 4 presents a summary of the test results, including the compressive strength, elastic modulus values, and the predicted values in accordance with the current American Concrete Institute (ACI) 318 specifications. The predicted elastic modulus value, $E_{c}=0.077\left(m_{c}\right)^{1.5}\left(f_{c}\right)^{0.5}$, is computed based on the unit weight of the concrete mixture $\left(m_{c}\right)$ and the compressive concrete strength $\left(f_{c}\right)$. A similar compressive concrete strength value was obtained for both concrete mixtures. However, a lower elastic modulus value was obtained for the HVFAC mixture than for the OPC mixture. This outcome was due to the low unit weight of the HVFAC mixture that is caused by the low unit weight of fly ash compared to the weight of cement. These results are in good agreement with those found in the literature [1].

3.2. Failure Mode and Load versus Displacement Relationship. Figure 3 presents typical failure modes of the axially loaded column specimens. No significant concrete spalling occurred during the axial load tests. Shear failure in specimens N-250 and F-150 occurred at failure. Similar failure patterns were observed for each specimen regardless of whether HVFA was present. 


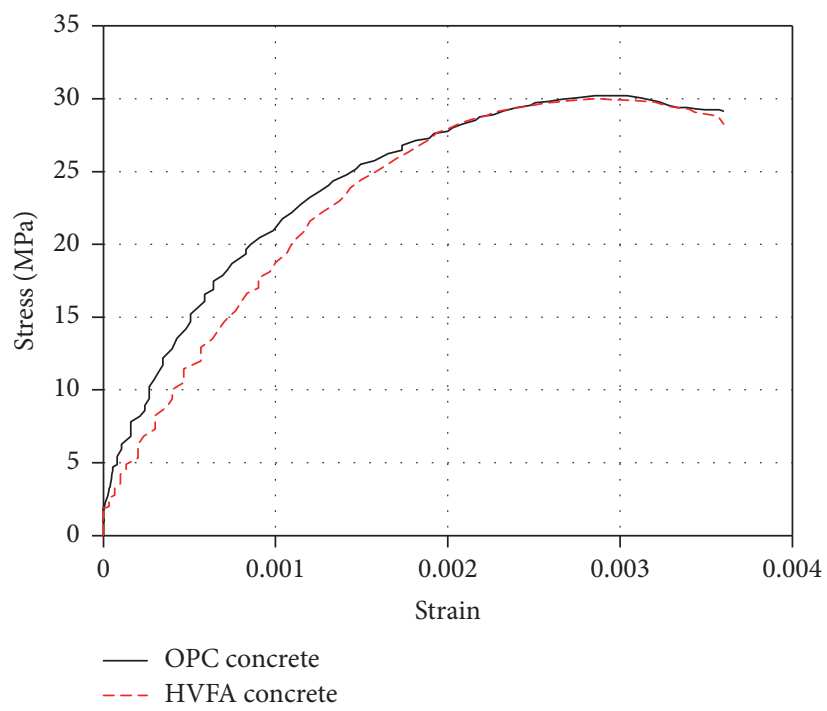

FIGURE 2: Stress-strain relationship in compression.

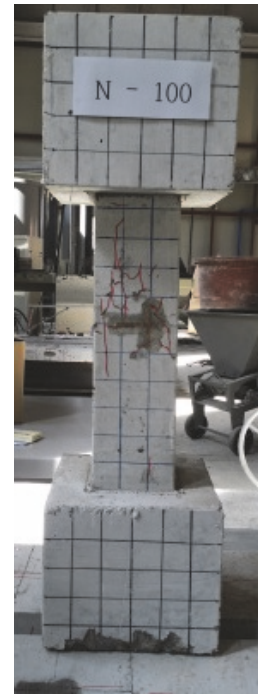

$\mathrm{N}-100$

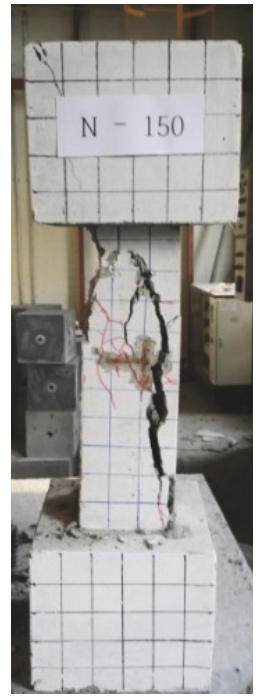

N-150

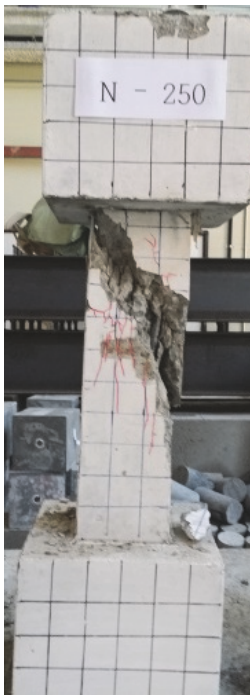

$\mathrm{N}-250$

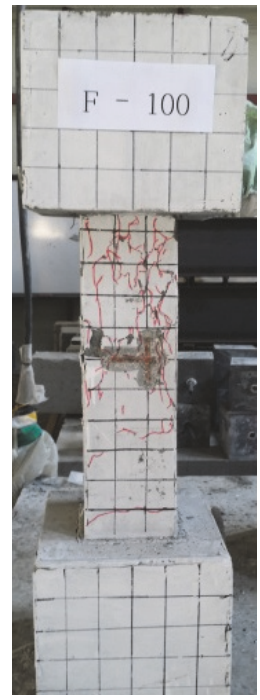

F-100

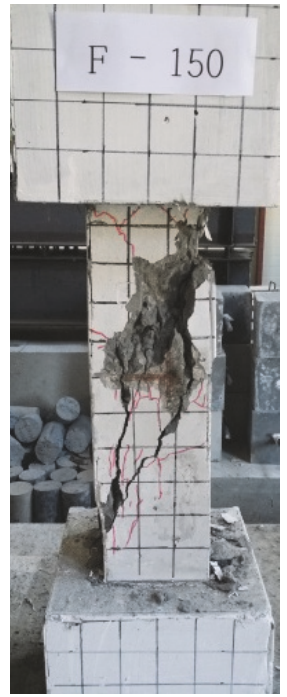

F-150

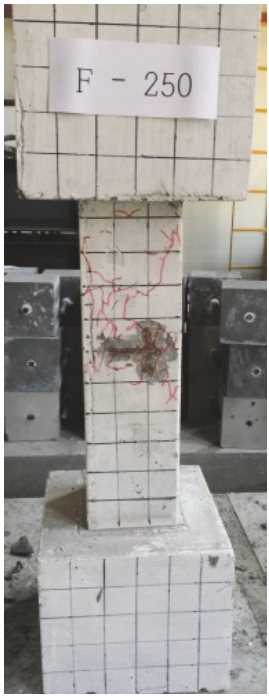

F-250

FIGURE 3: Failure modes of specimens.

Figure 4 shows the load versus displacement relation. The load-carrying capacity of the columns rapidly decreased after reaching the peak load. This behavior is consistent with that observed in similar RC columns with OPC. The ultimate load for the specimens, regardless of whether they contained HVFA, tended to decrease with an increase in the spacing of the transverse steel due to confining pressure.

Table 5 shows the measured axial loads at the yield of the longitudinal reinforcement and at the ultimate points. The ratio of the yield load to the ultimate load for the specimens with OPC is in the range of 0.73 to 0.79 , and the ratio of the yield load to the ultimate load for the specimens with HVFA is in the range of 0.75 to 0.84 . The ultimate load for both series of tests tended to increase with an increase in the tie reinforcement ratio. The ultimate design axial strength of a column $\left(\phi P_{n}\right)$ was computed using the equation found in ACI 318-16: $P_{n}=0.8 *\left(0.85 f^{\prime}{ }_{c}\left(A_{g}-A_{s}\right)+\right.$ $\left.f_{y} \cdot A_{s}\right)$. The measured longitudinal reinforcement strain levels reached the yield strain at the ultimate point, so the measured yield strength of the longitudinal reinforcement was used for the calculation. The predicted ultimate design strength of the RC columns with HVFA led to failure at loads ranging from 54 percent to 57 percent of the measured peak strength. The computed values conservatively predicted the measured values, and, thus, the existing equation in the ACI code is feasible for confined RC columns that contain HVFA. 

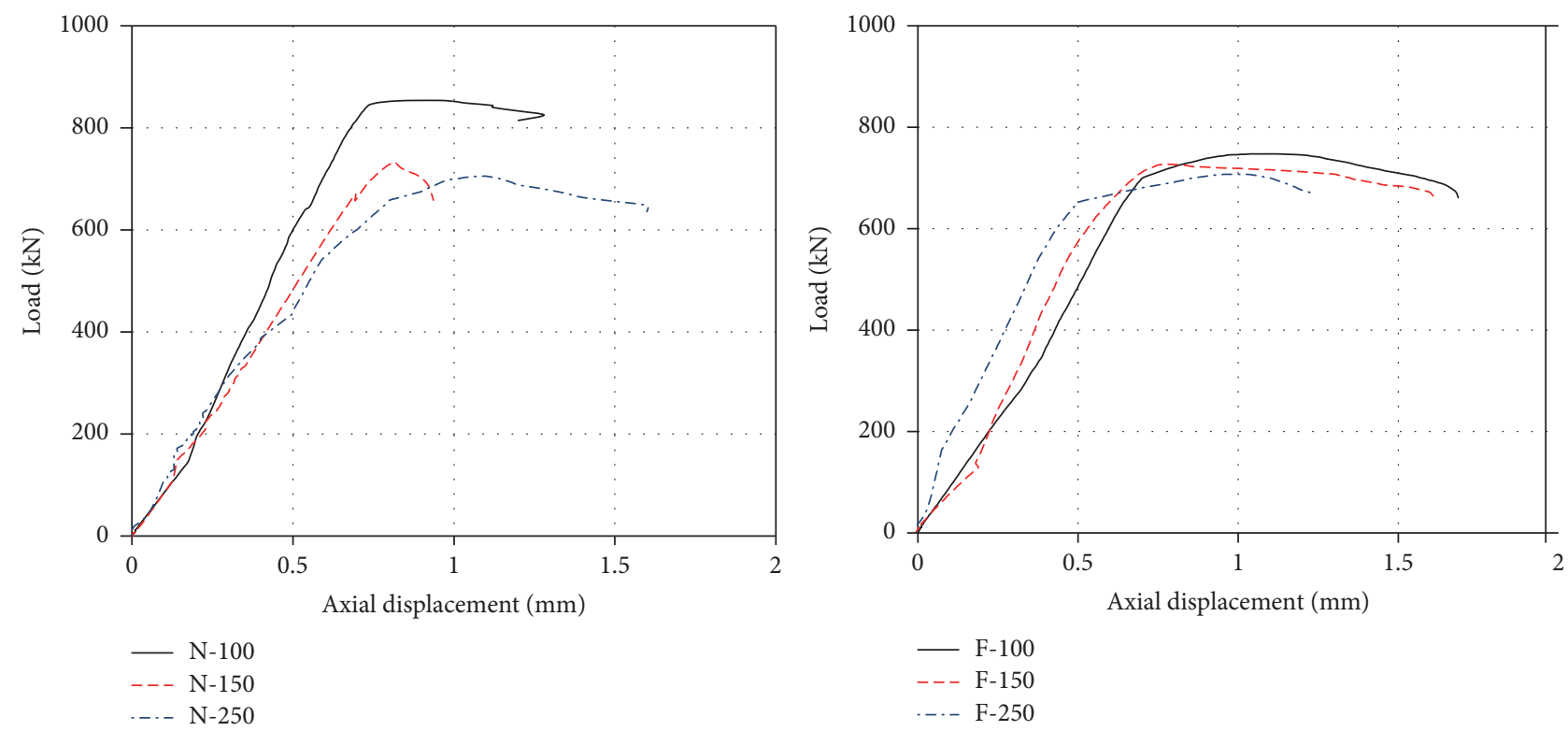

Figure 4: Load versus displacement relationship.

TABLE 5: Measured axial strength values at yield and ultimate points.

\begin{tabular}{|c|c|c|c|c|c|}
\hline ID & $P_{y}(\mathrm{kN})$ & $P_{\max }(\mathrm{kN})$ & $P_{y} / P_{\max }$ & $\phi P_{n}(\mathrm{kN})$ & $\phi P_{n} / P_{\max }$ \\
\hline N-100 & 626.8 & 854.0 & 0.73 & 406 & 0.48 \\
\hline N-150 & 548.8 & 732.8 & 0.75 & 406 & 0.55 \\
\hline N-250 & 559.0 & 705.8 & 0.79 & 406 & 0.58 \\
\hline F-100 & 625.5 & 747.2 & 0.84 & 400 & 0.54 \\
\hline F-150 & 673.5 & 727.1 & 0.93 & 400 & 0.55 \\
\hline F-250 & 531.6 & 707.7 & 0.75 & 400 & 0.57 \\
\hline
\end{tabular}

3.3. Concrete Strain of Specimens. Figure 5 shows the measured concrete strain values in the axial and lateral directions. In the early stages, the response was a relatively linear relationship between the axial strain and the lateral strain of the concrete; subsequently, nonlinear responses in the lateral strain beyond $\varepsilon_{l}=0.0005$ were experienced. The axial strain at peak stress was assumed to be axial strain of 0.002 [17]; however, this lateral strain value varied depending on the tie reinforcement ratio.

3.4. Effects of Tie Reinforcement Ratio. Figure 6 shows the relation between the load and strain for the longitudinal steel, including the load when the longitudinal steel yielded. For all the tested columns, the longitudinal steel yielded. However, the strain of the transverse rebar for all the specimens did not reach yield strain, so a confinement effect for the columns hardly was observed in the study. Similar patterns were observed irrespective of the presence of HVFA.

\section{Analytical Stress-Strain Models for Confined RC Columns}

The modified Kent and Park model [18], which was developed based on the second-order parabola model, allows simplicity and accuracy and thus is widely adopted in the literature. In the modified Kent and Park model, the monotonic concrete stress-strain relationship in compression is described as presented in

$$
\begin{aligned}
& f_{c}=K f_{c c}\left[2\left(\frac{\varepsilon_{c}}{\varepsilon_{c c}}\right)-\left(\frac{\varepsilon_{c}}{\varepsilon_{c c}}\right)^{2}\right] \quad \varepsilon_{c} \leq \varepsilon_{c c} \\
& f_{c}=K f_{c c}\left[1-Z\left(\varepsilon_{c}-\varepsilon_{c c}\right)\right] \geq 0.2 K f_{c}^{\prime} \quad \varepsilon_{c} \geq \varepsilon_{c c},
\end{aligned}
$$

where the concrete strain at the peak compressive stress is $\varepsilon_{c c}=0.002 K ; K=1+\rho_{s} f_{y h} / f_{c c}$ is a factor that accounts for the increase in strength that is due to confinement; the strain softening slope is $Z=0.5 /\left(\left(\left(3+0.29 f_{c c}\right) /\left(145 f_{c c}-\right.\right.\right.$ $\left.1000))+0.75 \rho_{s} \sqrt{h^{\prime} / S_{h}}-0.002 K\right) ; f_{c c}$ is the ultimate concrete compressive strength $(\mathrm{MPa}) ; f_{y h}$ is the yield strength of the transverse steel $(\mathrm{MPa}) ; \rho_{s}$ is the ratio of the volume of the transverse steel to the volume of the concrete core measured to the outside of the stirrups; $h^{\prime}$ is the width of the concrete core measured to the outside of the stirrups; and $s_{h}$ is the center-to-center spacing of the stirrups. 


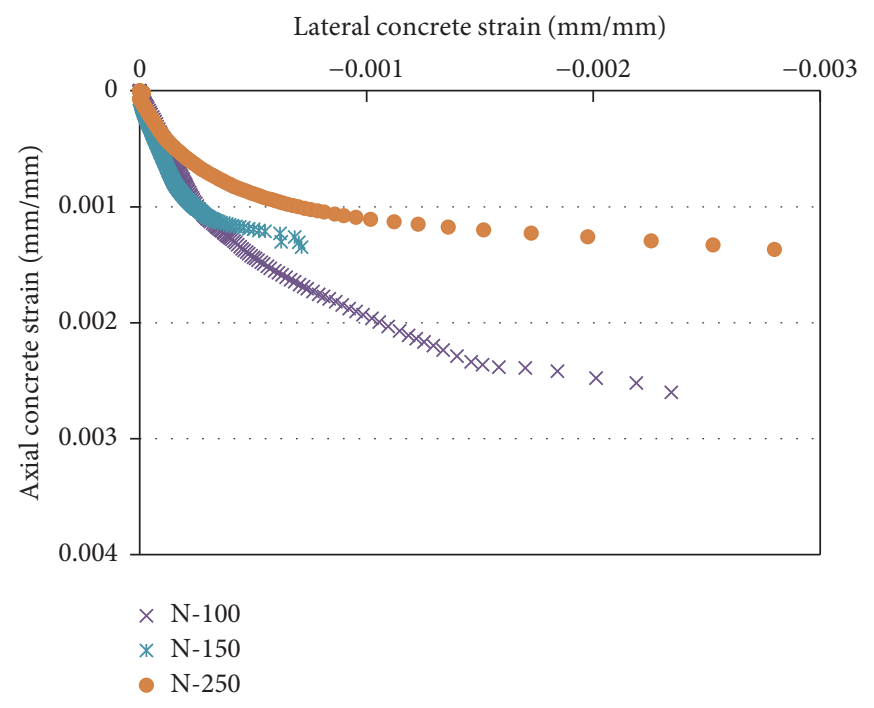

(a) Columns with OPC

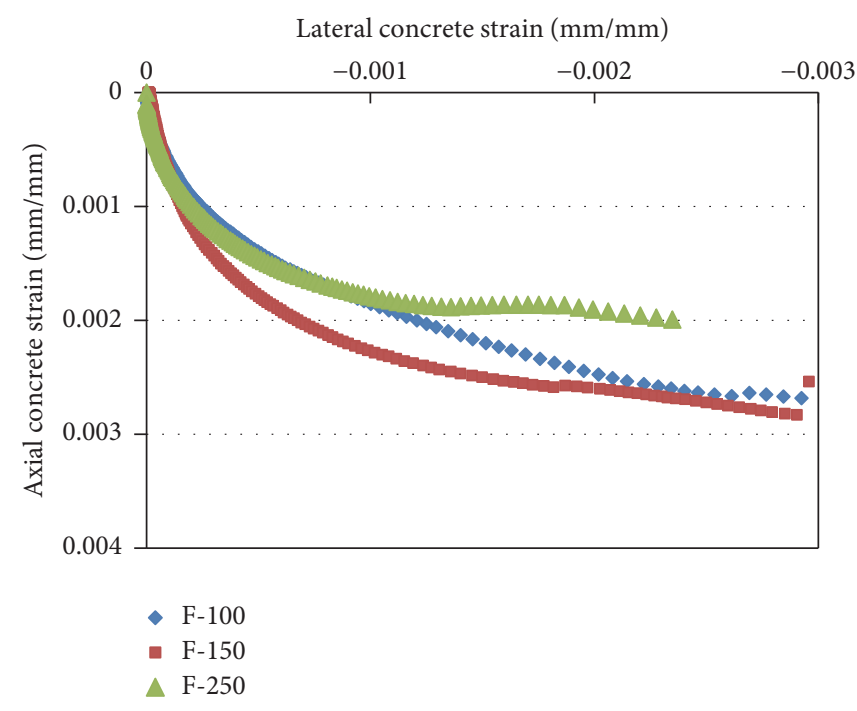

(b) Columns with HVFA

FIgURE 5: Axial versus lateral concrete strain of specimens.

Hoshikuma et al. [19] adopted an exponential function to simplify the expression for the ascending part, shown here as

$$
f_{c}=E_{c} \varepsilon_{c}\left\{1-\frac{1}{n}\left(\frac{\varepsilon_{c}}{\varepsilon_{c c}}\right)^{n-1}\right\}
$$

where $\varepsilon_{c c}$ is the strain at peak stress, $E_{c}$ is the initial stiffness (MPa), and $n$ is a coefficient.

Also, the descending part of the stress curve can be modeled from the test results by a straight line, as expressed in

$$
f_{c}=f_{c c}-E_{\mathrm{des}}\left(\varepsilon_{c}-\varepsilon_{c c}\right)
$$

where $E_{\text {des }}$ is the gradient at the descending part ( $\mathrm{MPa}$ ) $\left(E_{\text {des }}=\left(11.2 \cdot f_{c o}{ }^{2}\right) /\left(\rho_{s} \cdot f_{y h}\right)\right)$.

Figure 7 presents comparisons of the experimental results and the analytical model results. The experimental results for the specimens with OPC are consistent with the results obtained from the analytical modified model proposed by Kent and Park [18] and the Hoshikuma et al. model [19] irrespective of the confinement spacing. On the other hand, the experimental results of the specimens with HVFAC were slightly overestimated by the analytical modified model of Kent and Park but matched relatively well with the proposed equation by Hoshikuma. Therefore, the Hoshikuma equation was employed in this study to develop a modified analytical model for confined RC columns with HVFAC.

The adopted Hoshikuma equation was calibrated by adjusting the initial stiffness value $\left(E_{c}\right)$ of the HVFAC and the peak concrete strain that is due to the low unit weight of HVFA. Equations (4) and (5) are proposed for the initial stiffness value $\left(E_{c}\right)$ of RC columns with HVFA and the strain at peak stress $\left(\varepsilon_{c c}\right)$, respectively.

$$
\begin{aligned}
E_{c} & =0.077 m_{c}^{1.5} \cdot \sqrt[3]{f_{c}} \\
\varepsilon_{c c} & =0.002\left(\frac{2,300}{m_{c}}\right)^{1.5}+0.033 \beta \frac{\rho_{s h} f_{y h}}{f_{c}},
\end{aligned}
$$

where $\beta$ is a modification factor that depends on the section shape; for a square section, 0.4 is used by Hoshikuma et al. [19].

Figure 8 presents comparisons between the measured stress-strain values of the specimens using the proposed equations with modification of the elastic modulus values for the HVFAC mixture. The ascending part and descending part of the proposed stress-strain curves show good agreement with the measured envelopes.

Figure 9 shows that available experimental results in the literature [20] were compared with the proposed equation and confirmed that the stiffness of the specimen containing fly is less than that of the specimen without fly ash. The proposed equation properly predicts the stress-strain envelope for the column specimens containing fly ash.

The proposed equation was driven by limited experimental tests, and the results of the previous studies on HVFA concrete were insufficient for verification. Further study on the compressive behavior of HVFA concrete is needed. If a lot of experimental data are accumulated, it will be necessary to do further studies on the basis of the formula proposed.

\section{Conclusions}

Six specimens were tested in this study to develop an analytical stress-strain model for confined RC columns that contain HVFA. Based on the limited experimental results, 

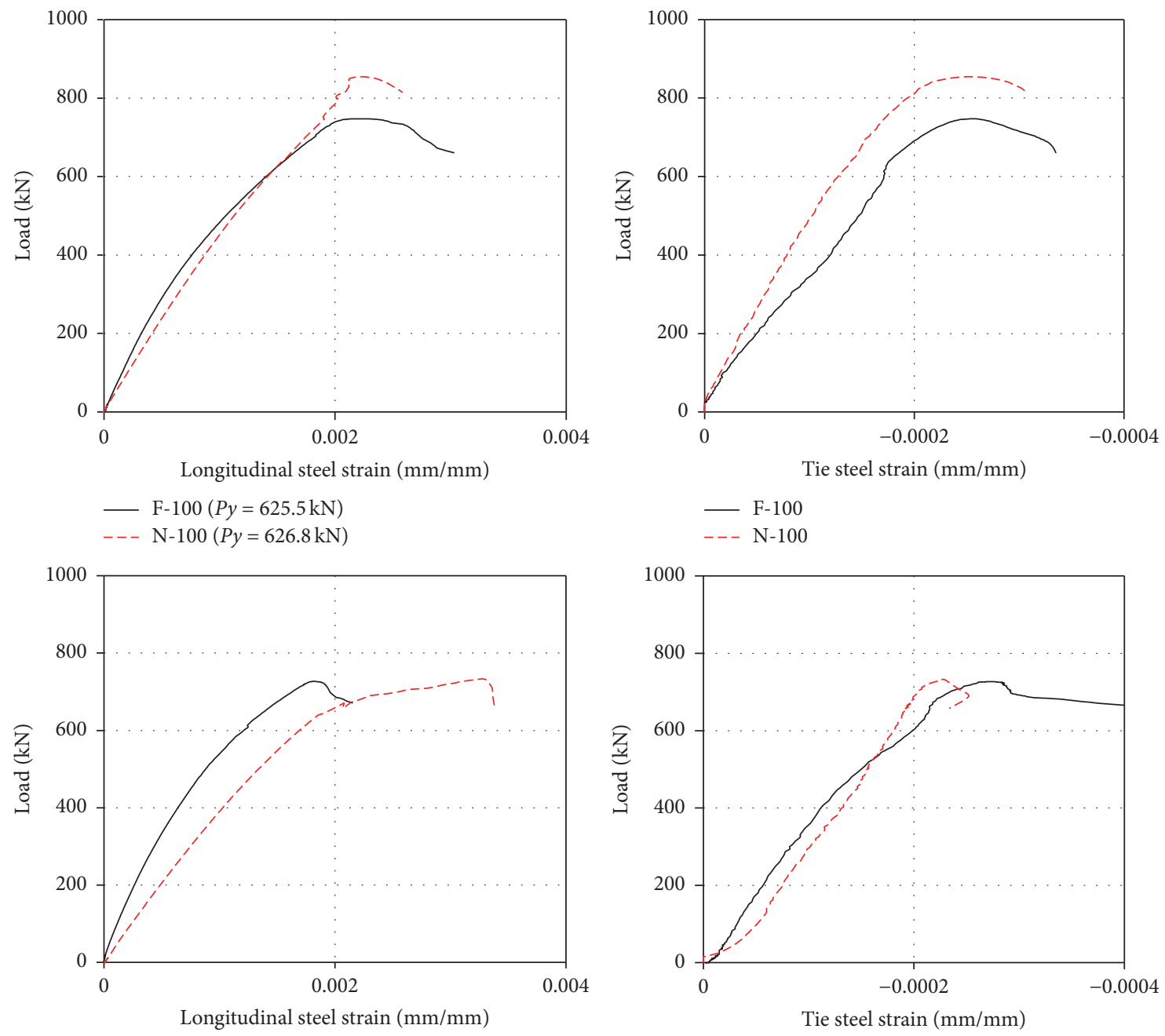

- F-150 $(P y=673.5 \mathrm{kN})$

-- N-150 $(P y=548.8 \mathrm{kN})$
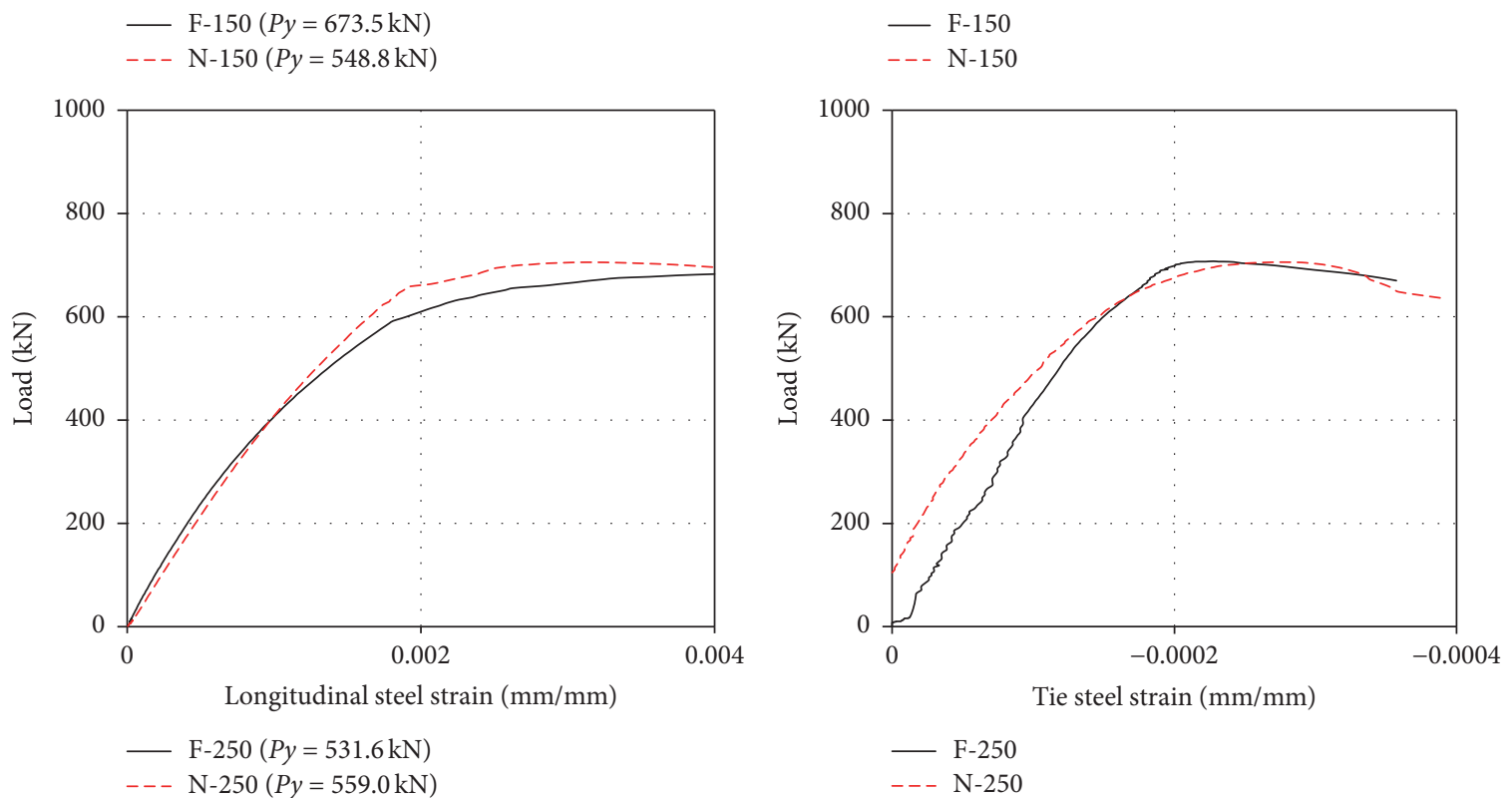

FIGURE 6: Load versus strain relationship of longitudinal steel for the specimens. 

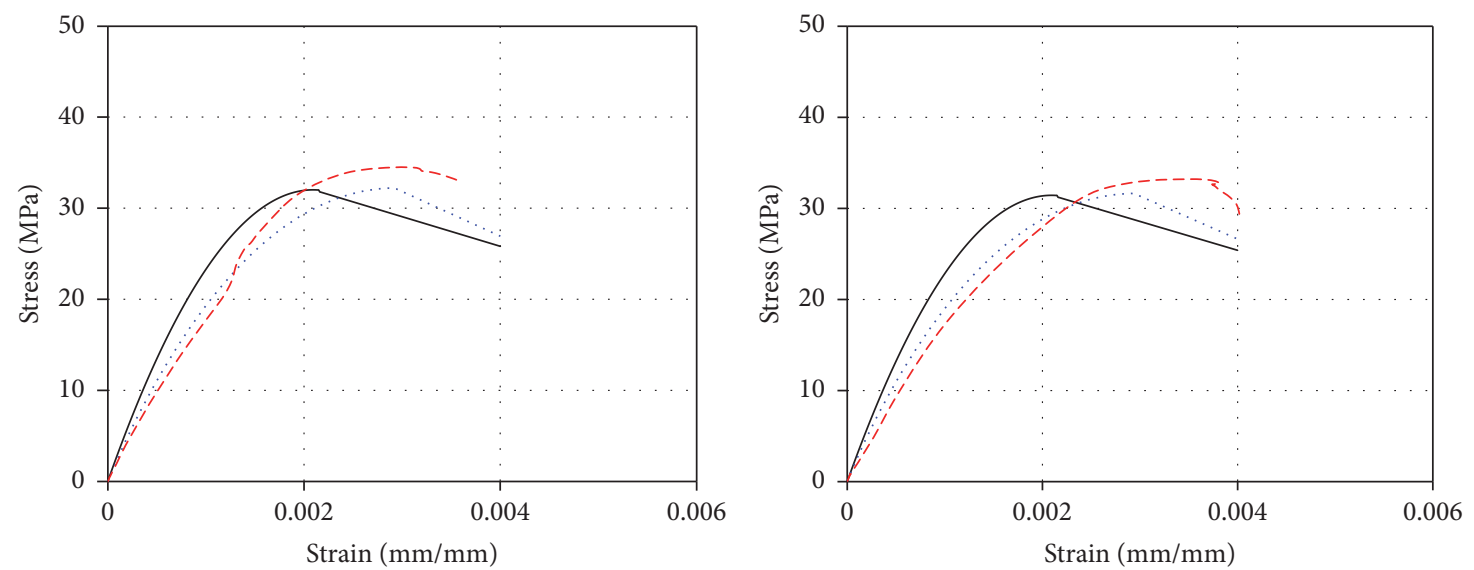

_ Modified Kent \& Park

Hoshikuma et al.

-- N-100: experiment

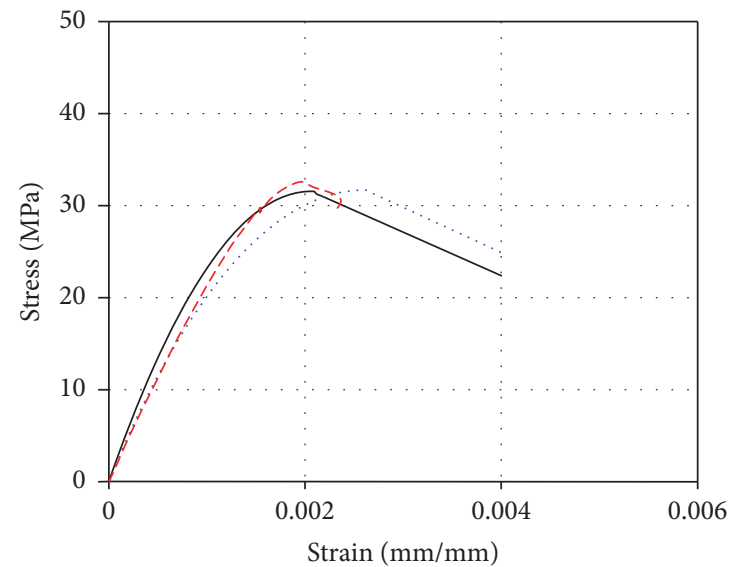

— Modified Kent \& Park Hoshikuma et al.

--- N-150: experiment

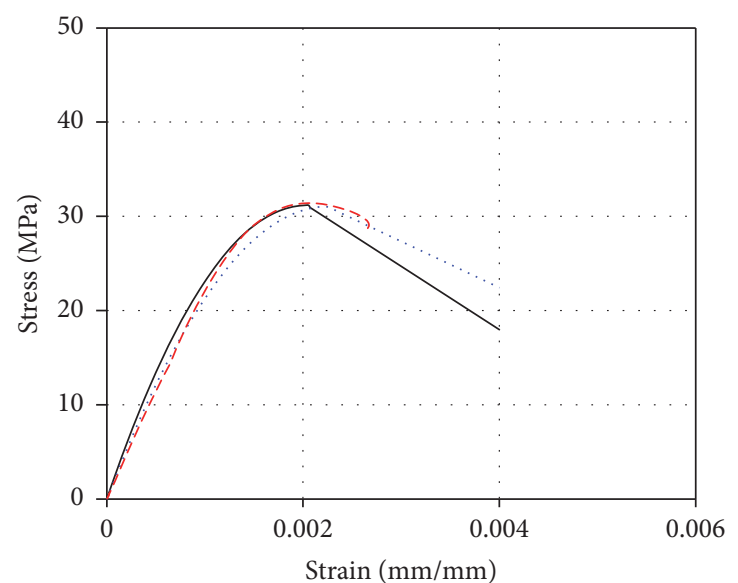

Modified Kent \& Park

Hoshikuma et al.

- - N-250: experiment
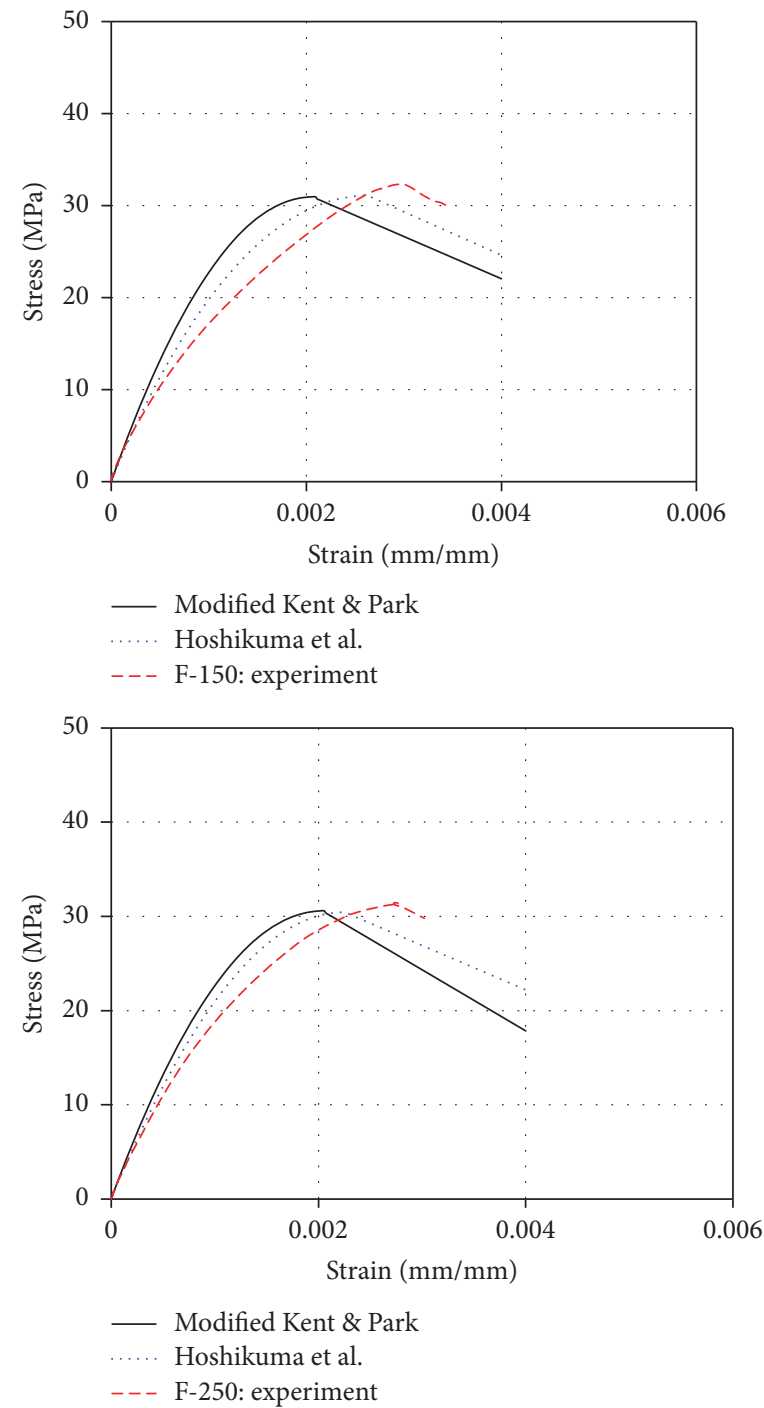

— Modified Kent \& Park

Hoshikuma et al.

- - F-100: experiment

_ Modified Kent \& Park

Hoshikuma et al.

-- F-150: experiment

FIGURE 7: Comparisons of the experimental results and analytical model results. 

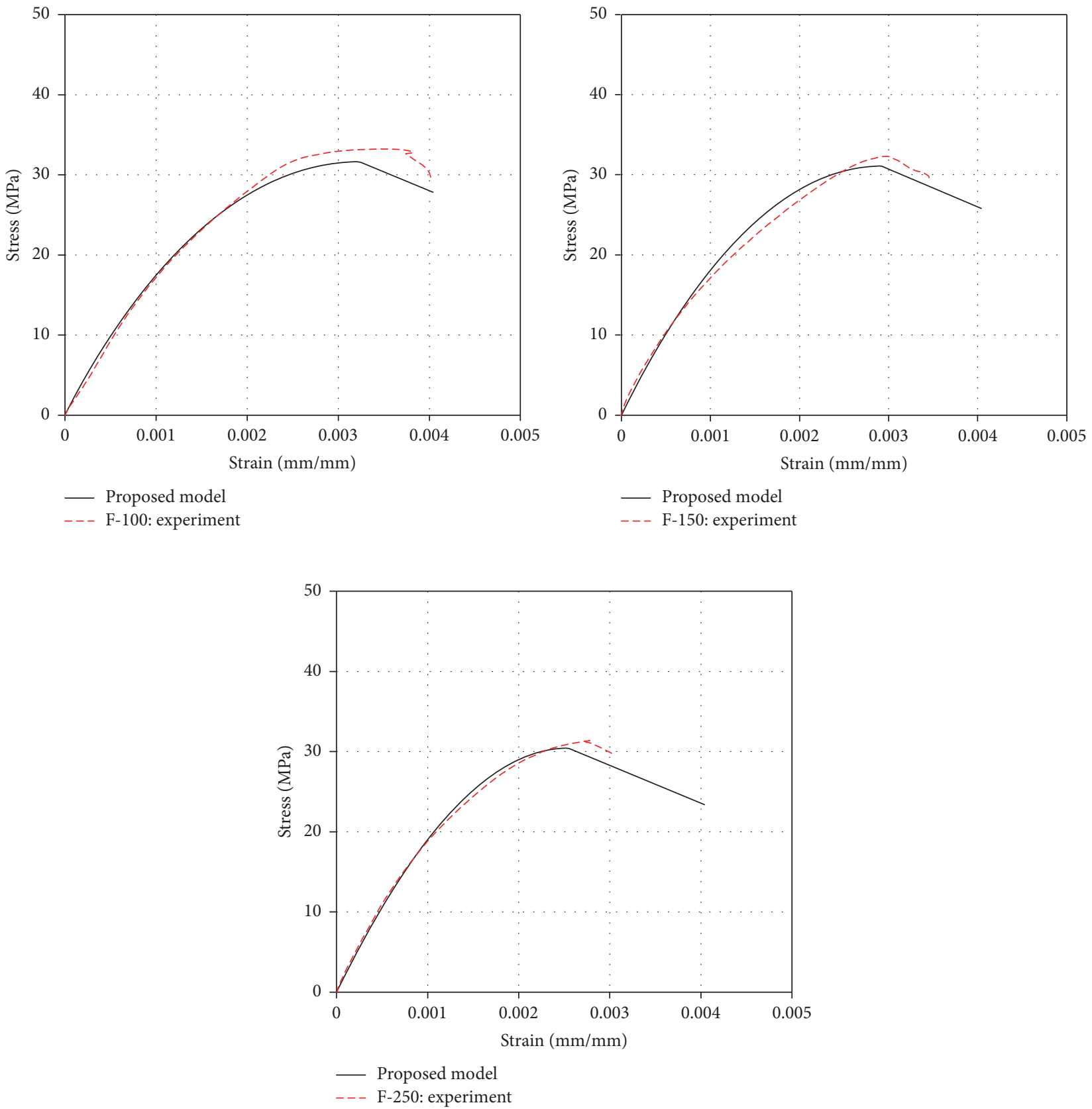

FIGURE 8: Comparisons between the experimental results and the proposed equation.

a stress-strain envelope for RC columns with HVFA was derived analytically and then calibrated using the experimental results. The following conclusions can be drawn with regard to the compressive behavior of the OPC and HVFAC mixes.

The elastic modulus values of the HVFAC mix were lower than those of the OPC mix. This outcome was due to the different water-to-binder ratio and low unit weight of the HVFAC mixture that is caused by the low specific gravity of its inherent fly ash compared to the weight of cement. Meanwhile, the compressive behavior of the HVFAC and OPC columns was similar with regard to crack morphology and crack progression. The maximum load-carrying capacity of the columns with HVFA tended to decrease up to 14 percent compared to the columns with OPC. The RC column elements made with HVFA behaved similarly, as expected, based on the equation used to predict OPC column behavior. Existing design standards will conservatively predict the ultimate capacity of HVFAC columns.

The initial stiffness of a column affects the elastic modulus of HVFAC; therefore, the proposed modified elastic modulus equation allows for adjustment of the initial stiffness value of concrete columns that contain HVFA. The modified 

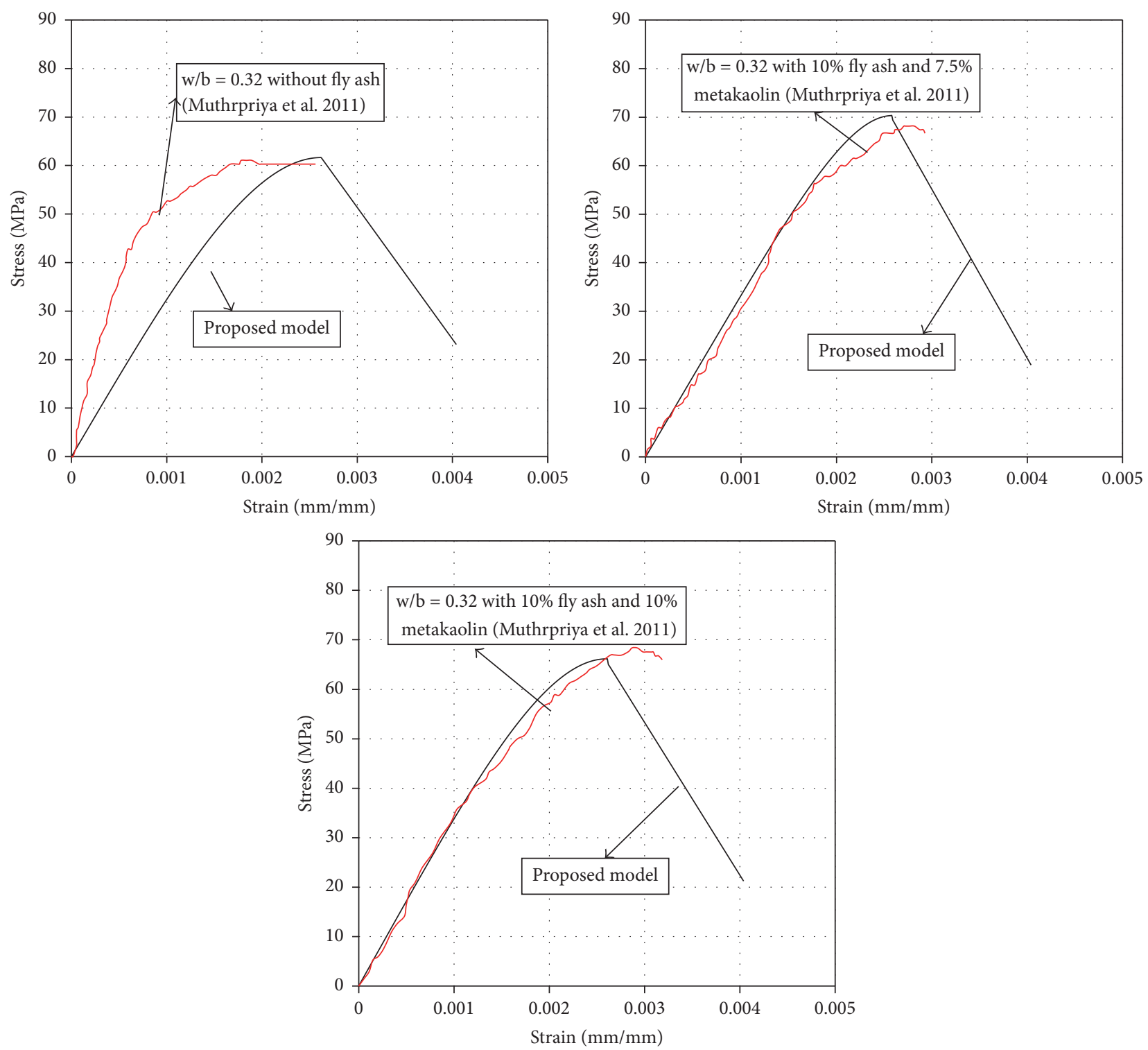

FIGURE 9: Comparisons between the available experimental result in the literature and the proposed equation.

stress-strain model can predict both the ascending and descending branches of the curve for confined RC columns with HVFA.

\section{Conflicts of Interest}

The authors declare that there are no conflicts of interest regarding the publication of this paper.

\section{Acknowledgments}

This research was financially supported by the Korean Ministry of Environment as "Public Technology Program Based on Environmental Policy" (no. 2016000700003).

\section{References}

[1] R. Siddique, "Performance characteristics of high-volume Class F fly ash concrete," Cement and Concrete Research, vol. 34, no. 3, pp. 487-493, 2004.

[2] K. Mala, A. K. Mullick, K. K. Jain, and P. K. Singh, "Effect of relative levels of mineral admixtures on strength of concrete with ternary cement blend," International Journal of Concrete Structures and Materials, vol. 7, no. 3, pp. 239-249, 2013.

[3] V. M. Malhotra, "Durability of concrete incorporating highvolume of low-calcium (ASTM Class F) fly ash," Cement and Concrete Composites, vol. 12, no. 4, pp. 271-277, 1990.

[4] T. R. Naik, B. W. Ramme, and J. H. Tews, "Use of high volumes of Class C and Class F fly ash in concrete," Cement, Concrete and Aggregates, vol. 16, no. 1, pp. 12-20, 1994. 
[5] D. Cross, J. Stephens, and J. Vollmer, "Structural applications of 100 percent fly ash concrete," in Proceedings of the World of Coal Ash (WOCA), pp. 1-9, Springer, Lexington, Kentucky, USA, 2005.

[6] J.-E. Kim, W.-S. Park, Y.-I. Jang et al., "Mechanical Properties of Energy Efficient Concretes Made with Binary, Ternary, and Quaternary Cementitious Blends of Fly Ash, Blast Furnace Slag, and Silica Fume," International Journal of Concrete Structures and Materials, vol. 10, no. 3, pp. 97-108, 2016.

[7] T. R. Naik and S. S. Singh, "Influence of fly ash on setting and hardening characteristics of concrete systems," ACI Materials Journal, vol. 94, no. 5, pp. 355-360, 1997.

[8] C. H. Huang, S. K. Lin, C. S. Chang, and H. J. Chen, "Mix proportions and mechanical properties of concrete containing very high-volume of Class F fly ash," Construction and Building Materials, vol. 46, pp. 71-78, 2013.

[9] G. Venkatesan, S. Reghu Raman, and M. Chandra Sekaran, "Flexural behavior of reinforced concrete beams using high volume fly ash concrete confinement in compression zone," Journal of Civil Engineering (IEB), vol. 41, no. 2, pp. 87-97, 2013.

[10] M. Arezoumandi, C. A. Ortega, and J. S. Volz, "Flexural behavior of high-volume fly ash concrete beams-experimental study," Transportation Research Record, vol. 2508, pp. 22-30, 2015.

[11] M. Arezoumandi, J. S. Volz, and J. J. Myers, "Shear behavior of high-volume fly ash concrete versus conventional concrete," Journal of Materials in Civil Engineering, vol. 25, no. 10, pp. 15061513, 2013.

[12] R. Thangaraj and R. Thenmozhi, "Experimental study on rc beams using high volume fly ash," IRA-International Journal of Technology \& Engineering, vol. 3, no. 2, pp. 71-85, 2016.

[13] V. V. Cao and H. R. Ronagh, "A model for damage analysis of concrete," Advances in Concrete Construction, vol. 1, no. 2, pp. 187-200, 2013.

[14] M. K. M. Reddar, Stress-strain model of Unconfined and Confined Concrete and Stress-Block Parameters, Master Thesis [Master, thesis], University of Texas A \& M, College Station, Tex, USA, 2009.

[15] T. Tavio and A. Tata, "Predicting Nonlinear behavior ad stressstrain relationship of rectangular confined reinforced concrete columns with ANSYS," Civil Engineering Dimension, vol. 11, no. 1, pp. 23-31, 2009.

[16] S. W. Yoo, S. H. Jung, and S.-J. Kwon, "Evaluation of compressive and shear strength characteristics in high volume fly ash concrete," Applied Mechanics and Materials, vol. 584-586, pp. 1282-1288, 2014.

[17] M. H. Harajli, E. Hantouche, and K. Soudki, "Stress-strain model for fiber-reinforced polymer jacketed concrete columns," ACI Structural Journal, vol. 103, no. 5, pp. 672-682, 2006.

[18] D. C. Kent and R. Park, "Flexural members with confined concrete," Journal of the Structural Division, vol. 97, no. 7, pp. 1969-1990, 1971.

[19] J. Hoshikuma, K. Kawashima, K. Nagaya, and A. W. Taylor, "Stress-strain model for confined reinforced concrete in bridge piers," Journal of Structural Engineering, vol. 123, no. 5, pp. 624633, 1997.

[20] P. Muthupriya, K. Subramanian, and B. G. V. Vishnuram, "Investigation of Behaviour of high performance reinforced concrete columns with metakaolin and fly ash as admixture," International Journal of Advanced Engineering Technology, vol. 2, no. 1, pp. 190-202. 

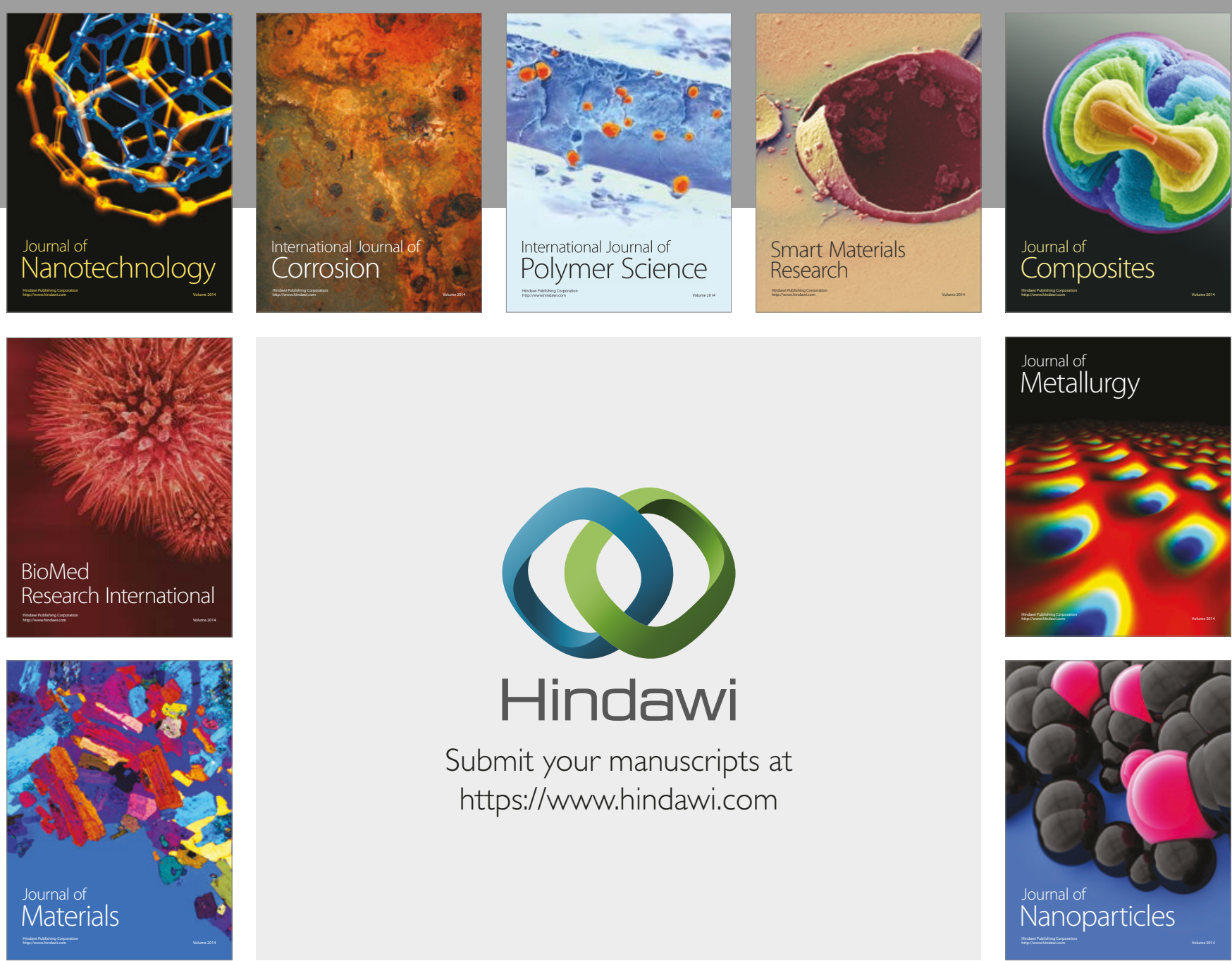

\section{Hindawi}

Submit your manuscripts at

https://www.hindawi.com
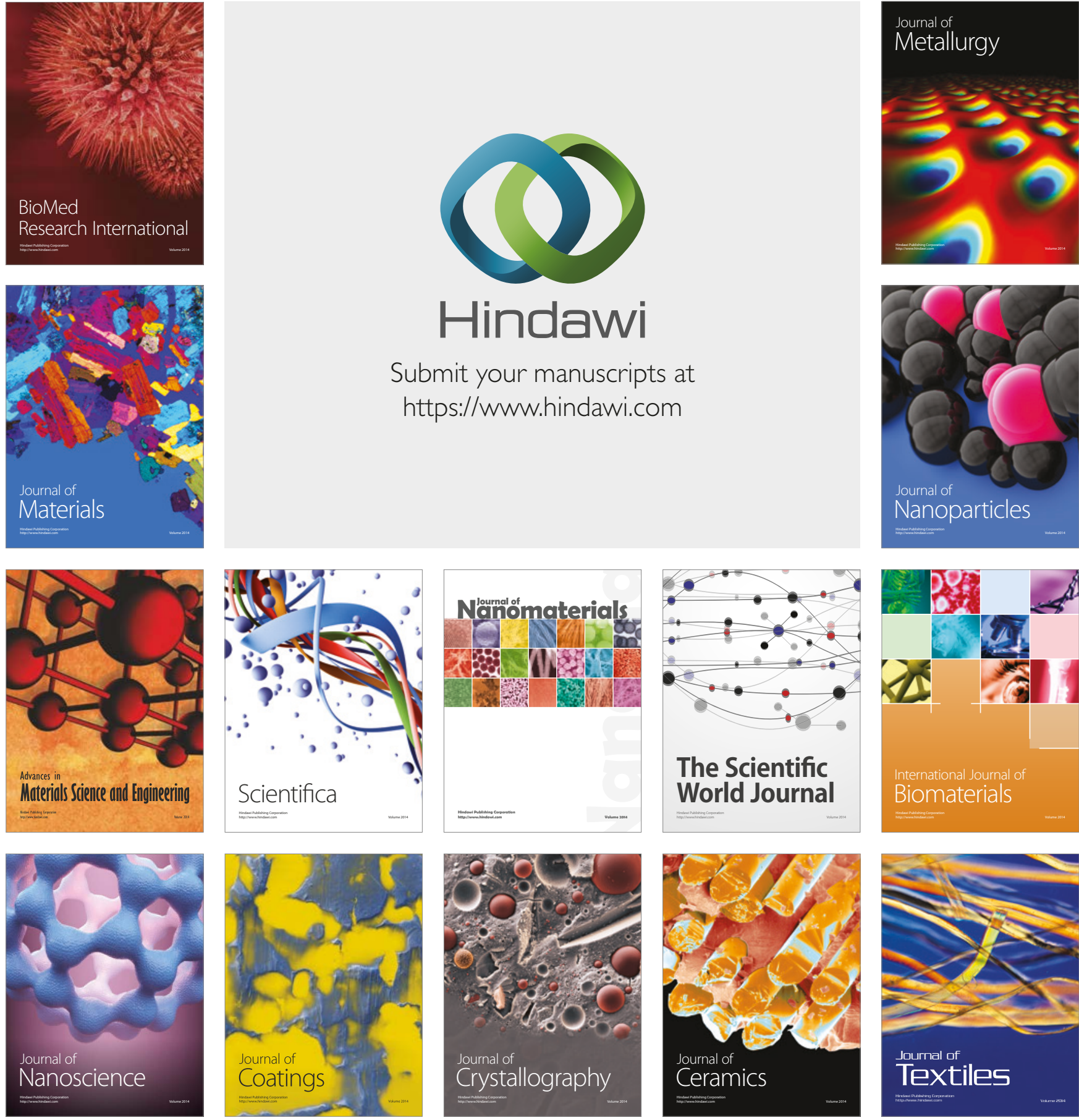

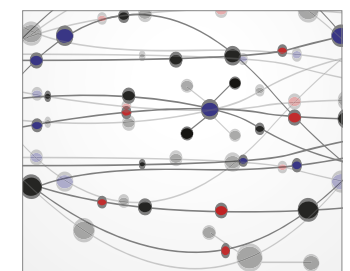

The Scientific World Journal
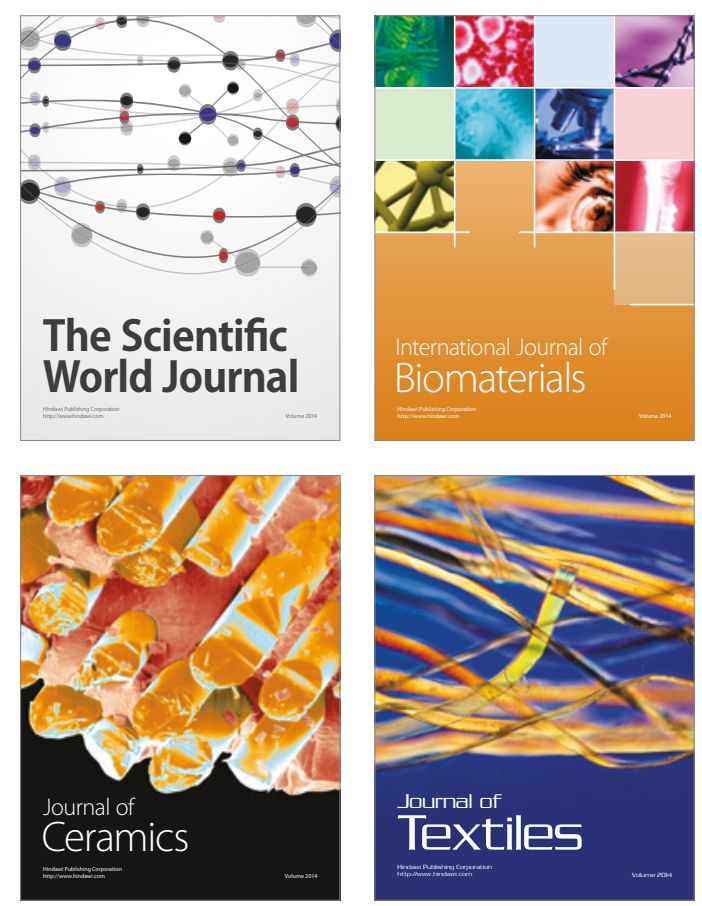